\title{
Impact of Consumption of Olive and Argane Oils on Anthropometric Profile of Postmenopausal Women in Morocco
}

Hanane Labraimi ${ }^{1}$, Mohamed El Mzibri ${ }^{2}$, Abdelfettah Derouiche ${ }^{3}$, Zoubida Charrouf ${ }^{4}$, Amina Barkat ${ }^{5}$, Khalid El Kari $^{2}$, Hassan Aguenaou ${ }^{2}$ and Najat Mokhtar ${ }^{2}$

1. High Institute of Nursing Professions and Health, Rabat 10000, Morocco

2. Joint Unit of Research in Nutrition and Alimentation (URAC 39), University Ibn Tofail/CNESTEN, Rabat 10000, Morocco

3. Joint Unit of Research in Nutrition and Alimentation (URAC 39), University Ibn Tofail/University Hassan II, Mohammadia, Casablanca 20000, Morocco

4. Joint Unit of Research in Nutrition and Alimentation (URAC 39), Sciences Faculty, University Mohammed V, Rabat 10000, Morocco

5. National Center of Reference in Neonatology and Nutrition, Children Hospital of Avicenne/Unit of Research in Nutrition and Alimentation (URAC 39), University Ibn Tofail, Rabat 10000, Morocco

\begin{abstract}
Worldwide, large studies have shown that the menopause is mainly associated with substantial changes in body composition that result in an increase in waist circumference, fat accumulation and specially weight gain. This overweight could be exacerbated by fat intake. Thus, this study was planned to evaluate the impact of the consumption of olive and argane oils on anthropometric profile and body composition of postmenopausal women. The nutritional intervention was conducted over a period of eight weeks, involving daily consumption of $25 \mathrm{~mL}$ of argane oil or olive oil in 151 postmenopausal women (55.49 \pm 6.18 years old). The anthropometric profile (weight, height and body mass index (BMI)) and body composition (fat mass (FM) and lean mass (LM)) were determined at 0 week (baseline), and after the 4 th and 8 th weeks of nutritional intervention. Results clearly demonstrated that argane oil or olive oil consumption did not affect the anthropometric parameters and the body composition of postmenopausal women. Thus, argane and/or olive oils' regular diet does not lead to weight gain, and postmenopausal women could benefit from their impact on health for a better quality of life and to overcome all menopause associated problems. A longer period of nutritional intervention is required to confirm the trend down that was recorded.
\end{abstract}

Key words: Olive oil, argane oil, anthropometry, postmenopausal women.

\section{Introduction}

Menopause is a normal physiological process that marks the end of the fertile period for women, the cessation of ovarian function and arrest of secretion of female hormones, estrogen and progesterone. It naturally occurs one year after the end of menstruation and can be artificially induced after surgical removal of ovaries (castration).

Corresponding author: Hanane Labraimi, assistant professor, research fields: public health, cancer and appetite, pregnancy and weight evolution.
Depending on the physiological status of women, menopause may be associated with a number of events, including hot flashes and substantial changes in body composition that result in an increase in waist circumference, fat accumulation and specially weight gain $[1,2]$. Indeed, during menopause, the decreased estrogen secretion results in a spontaneous increase in fat mass (FM) and decrease in muscle mass [3]. In addition, lower level of progesterone and estrogen production affects the thyroid activities, resulting in a slower metabolism and usually accompanied by 
weight gain [4].

In Morocco, like most Mediterranean countries, the diet is rich in fat intake, which is an average of 19.36 $\mathrm{kg} /$ person/year. Household surveys in 2001, conducted by the Department of Statistics showed that consumption of oils in general is averaged with 16.1 $\mathrm{kg} /$ person/year (Department of Statistics, Kingdom of Morocco, 1970 to 2001). In addition, lipids represent on averagely $38.5 \%$ of energy intake of men and $39.6 \%$ of women [5].

It is widely accepted that the impact of lipid intake on health is closely linked to their content of saturated and unsaturated fatty acids [6, 7]. Excessive consumption of unsaturated or trans fatty acids, appears to be an increased risk factor, in a convincing level, to develop overweight associated diseases $[6,7]$.

Most cross-sectional studies showed a positive correlation between the fat percentage in the diet and the obesity. Excessive fat intake can promote an imbalance between energy intake and energy expenditure, which could increase the risk of obesity [8]. Moreover, the association between weight gain inherent to menopause [1] and the one due to a diet with a high fat intake [8], is bad for menopausal women and can lead to an increased risk of cardiovascular disease, breast cancer and even of neurodegenerative diseases [9].

In Morocco, argane and olive oils play an important role in the national economy. This country is one of the main producers/suppliers of these oils worldwide. Moroccan people are also high consumers of argane and olive oils; these two oils are the basis of the diet in many parts of the country.

Olive and argane oils are products of great importance and their nutritional value has been recognized internationally. Over the years, the diet based on consumption of olive and/or argane oils became widely associated with better health and protection against cardiovascular diseases and cancers of the colon, breast and skin [10]. The beneficial effect is attributed to a favorable fatty acid profile and the presence of some minor components that are responsible for flavors and tastes of these oils $[11,12]$. In addition, olive and argane oils are traditionally used in Morocco for ointments skin care or soaps manufacture. More components of those two oils are a source of antioxidants and components with anti-inflammatory activity. Argane oil contains $80 \%$ of saturated fatty acids: palmitic acid, stearic acid and linoleic, which are known for their preventive role against cardiovascular diseases [13-15]. Schottenol and spinasterol are rarely found in vegetable oils and are characteristic of argane oil; these two molecules have probable anti-carcinogenic properties $[16,17]$.

Olive oil has great beneficial health properties. Large studies have been conducted and have reported that consumption of olive oil reduces the risk of cardiovascular diseases, due to the presence of vitamin A (3-30 $\mathrm{mg} / \mathrm{kg}$ of provitamin A carotene), vitamin $\mathrm{E}$ (150 $\mathrm{mg} / \mathrm{kg}$ of $\alpha$-tocopherol) and mono-unsaturated fatty acids [18]. Moreover, olive oil is rich on oleic acid, whose content may vary from $55 \%$ to $83 \%$. Finally, the tocopherol wealth of argane and olive oils gives them a strong antioxidant effect [19].

During recent decades, women have acquired a high awareness that weight gain during menopause is risk factor for developing various diseases, particularly cardiovascular disease [3].

To assess whether postmenopausal women can still enjoy the benefits of argane and olive oils, and to our knowledge that no study has been conducted on the impact of the consumption of these oils on the anthropometric profile of a population of postmenopausal women, the authors have planned to evaluate the impact of the consumption of these oils on anthropometric profile and body composition of postmenopausal women.

\section{Materials and Methods}

\subsection{Subjects and Recruitment}

The study was conducted on a sample of 151 postmenopausal women aged over 40 years old. 
Menopausal status was confirmed by blood analysis of follicule stimulating hormone (FSH), which must be less than $40 \mathrm{IU} / \mathrm{L}$ [20]. Women with diabetes, cardiovascular disease, hypo- or hyperthyroidism or digestive problems involving lipid malabsorption, were excluded from the study. The study was performed on consenting women after approval by the ethics committee of the Faculty of Medicine and Pharmacy of Rabat, Morocco.

\subsection{Oils}

Argane oil was purchased from the Targante cooperative (Arganati). Olive oil was kindly provided by the company Oued Souss.

\subsection{Protocol}

The study was conducted between October 2008 and July 2010. The population was randomly divided into two groups: group I (77 women) who consumed argane oil and group II (74 women) who consumed olive oil.

The nutritional intervention was preceded by a stabilization period of two weeks, in which all the participants consumed $25 \mathrm{~g}$ of a non-hydrogenated vegetable margarine. During this period, the participating women have consumed neither olive oil nor the argane oil.

For the eight weeks of nutritional intervention, group I received $25 \mathrm{~mL}$ of argane oil/d and group II $25 \mathrm{~mL}$ of olive oil/d. The measurements were taken at the end of stabilization period "baseline" $\left(\mathrm{T}_{0}\right)$, after four weeks $\left(T_{1}\right)$ and after eight weeks $\left(T_{2}\right)$ of intervention.

The caloric intake of oil was calculated on basis of the oil density $(0.92 \mathrm{~kg} / \mathrm{L}$ for argane oil as well as olive oil) and energy from fat intake $(9 \mathrm{kcal} / \mathrm{g})$. Also, the energy supply of argane oil and olive oil are both $207 \mathrm{kcal}$.

\subsection{Anthropometric Measurements}

Anthropometry was measured according to Refs. $[21,22]$. The body weight of participating women, dressed in light suits, was measured with a mechanical scale (150 $\pm 0.1 \mathrm{~kg}$, Seca 750, Germany). Standing height was taken barefoot, using a stadiometer (200 \pm $0.1 \mathrm{~cm}$, Seca 217, Germany). The body mass index (BMI, $\mathrm{kg} / \mathrm{m}^{2}$ ) was calculated based on Eq. (1) [23]:

$$
\text { BMI }\left(\mathrm{kg} / \mathrm{m}^{2}\right)=\text { weight } /(\text { height standing })^{2}
$$

Waist and hip circumference were measured using a centimeter tape $(220 \pm 0.1 \mathrm{~cm})$.

\subsection{Skinfolds}

All measurements were taken on the right side of the body. The selected sites are: triceps, biceps, supra-iliac and subscapular. Triceps fold is located in midway between the posterior surface of the arm, between the edge of the acromion and the olecranon, in the direction of the triceps length, held vertically with the arm. The biceps crease was measured using half of the arm as benchmarks, it is located on the front of the arm just above the center of the cubital fossa, the same level as the fold of the triceps. The skin is pinched in the direction of the length of the biceps, mid-distance, facing the front of the arm, the participant holding his bent arm. Subscapularis fold is just below the tip of the inferior angle of the scapula, is formed and oriented upwards and inwards at an angle of about $45^{\circ}$ with the vertical. The supra-iliac fold is just above the iliac crest in the mid-axillary line, vertical anterior edge of the armpit to the iliac crest. When measuring these four folds, the fold was kept clamped firmly between the thumb and forefinger, and slightly detached from the underlying tissue before applying the compass to measure. Folds determination was performed with a specially calibrated clip (adiposity-meter) to measure the fold thickness without overwriting the subcutaneous adipose tissue (the compass of Harpenden).

\section{$2.6 F M$}

Calculation of FM is done using the equation of Siri [23] as Eq. (2):

$$
\mathrm{FM}(\%)=[(4.95 / \text { body density })-4.51] \times 100(2)
$$


To calculate body density $(d)$, the following Eq. (3) was used:

$$
d=[c-m \times \log (\text { sum of skinfolds })]
$$

The two constants $c$ and $m$ were determined following the tables of Durnin based on age of participants and the number of skin folds used [23].

The fat was expressed per $\mathrm{kg}$ body weight.

\subsection{Body Lean Mass (LM)}

LM was obtained by subtracting the fat of the total body mass, considering the body as a two-compartment model.

\subsection{Statistical Analysis}

Data processing and statistical analysis were performed using the software "Statistical Package for the Social Science" (SPSS version 11.0).

\section{Results}

The average age of the study population is $55.4 \pm$ 6.1 years old. The population has an average size of $1.58 \pm 0.28 \mathrm{~m}$, with a minimum of $1.46 \mathrm{~m}$ and a maximum of $1.74 \mathrm{~m}$ (Table 1 ).
From $\mathrm{T}_{0}$ to $\mathrm{T}_{2}$, the effect of the consumption of olive or argane oils on the weight of postmenopausal women is reported in Table 2.

The results showed that the nutritional intervention neither based on argane oil (group I) nor olive oil (group II) cause significant changes in the weight of women, respectively, with $P=0.8068$ and $P=0.7580$. Consecutively, the BMI remains stable for both oils, with no significant difference (group I $P=0.9214$ and group II $P=0.07344$ ). However, for both groups, trend down could be recorded. This is noted for weight and waist circumference (WC) of postmenopausal women.

Moreover, the nutritional intervention did not exhibit any difference on the WC of participated women, either for the olive group or the argane group.

Body composition of female participants is reported in Table 3. The analysis of body fat in postmenopausal women, calculated from skin folds, showed an average of $40.57 \% \pm 4.80 \%$. Data analysis showed that the average population has an excess of FM $>28 \%$ for both the group who consumed argane oil (group I) and olive oil (group II). For both groups,

Table 1 General characteristics of the population at $\mathbf{T}_{\mathbf{0}}$.

\begin{tabular}{llll}
\hline Anthropometric characteristics & Group I $\left(\mathrm{T}_{0}\right)$ & Group II $\left(\mathrm{T}_{0}\right)$ & Tota of group I and II \\
\hline Age (year) & $55.5 \pm 6.1$ & $55.4 \pm 6.1$ & $55.4 \pm 6.1$ \\
Height $(\mathrm{m})$ & $1.58 \pm 0.05$ & $1.58 \pm 0.06$ & $1.58 \pm 0.28$ \\
Population size & 77 & 74 & 151 \\
\hline
\end{tabular}

Table 2 Anthropometric characteristics of the population at $\mathbf{T}_{\mathbf{0}}$ and $\mathbf{T}_{2}$.

\begin{tabular}{|c|c|c|c|c|c|c|}
\hline \multirow{2}{*}{$\begin{array}{l}\text { Anthropometric } \\
\text { characteristics }\end{array}$} & \multicolumn{3}{|c|}{ Group I } & \multicolumn{3}{|c|}{ Group II } \\
\hline & $\mathrm{T}_{0}$ & $\mathrm{~T}_{2}$ & $P\left(\mathrm{~T}_{0}-\mathrm{T}_{2}\right)$ & $\mathrm{T}_{0}$ & $\mathrm{~T}_{2}$ & $P\left(\mathrm{~T}_{0}-\mathrm{T}_{2}\right)$ \\
\hline Weight $(\mathrm{kg})$ & $69.6 \pm 10.9$ & $69.1 \pm 10.9$ & 0.8068 & $70.1 \pm 10.4$ & $69.6 \pm 10.5$ & 0.7580 \\
\hline BMI $\left(\mathrm{kg} / \mathrm{m}^{2}\right)$ & $27.7 \pm 4.3$ & $27.6 \pm 4.3$ & 0.9214 & $28.4 \pm 4.1$ & $28.1 \pm 4.1$ & 0.7344 \\
\hline $\mathrm{WC}(\mathrm{cm})$ & $89.8 \pm 10.8$ & $89.0 \pm 11.2$ & 0.7733 & $90.0 \pm 9.1$ & $89.8 \pm 9.8$ & 0.9227 \\
\hline Population size & 77 & & & 74 & & \\
\hline
\end{tabular}

$P$ means the statistical difference between $\mathrm{T}_{0}$ and $\mathrm{T}_{2}$.

Table 3 Body composition of the population for the two groups at $\mathbf{T}_{\mathbf{0}}$ and $\mathbf{T}_{2}$.

\begin{tabular}{|c|c|c|c|c|c|c|}
\hline \multirow{2}{*}{ Body composition } & \multicolumn{3}{|c|}{ Group I } & \multicolumn{3}{|c|}{ Group II } \\
\hline & $\mathrm{T}_{0}$ & $\mathrm{~T}_{2}$ & $P\left(\mathrm{~T}_{0}-\mathrm{T}_{2}\right)$ & $\mathrm{T}_{0}$ & $\mathrm{~T}_{2}$ & $P\left(\mathrm{~T}_{0}-\mathrm{T}_{2}\right)$ \\
\hline FM (\%) & $40.4 \pm 3.50$ & $40.22 \pm 3.21$ & 0.1004 & $40.75 \pm 3.48$ & $40.89 \pm 3.33$ & 0.6752 \\
\hline LM (kg) & $41.23 \pm 5.47$ & $41.12 \pm 5.49$ & 0.1576 & $41.79 \pm 5.19$ & $40.96 \pm 5.31$ & 0.7323 \\
\hline Population size & 77 & & & 74 & & \\
\hline
\end{tabular}

$P$ means the statistical difference between $\mathrm{T}_{0}$ and $\mathrm{T}_{2}$. 
body composition evaluated by free mass and LM, no difference was reported during the intervention period with $P>0.05$.

\section{Discussion}

Thus, postmenopausal women seek to take control of weight gain inherent to physiological change, mainly through diets limiting fat intake [3]. Furthermore, it is assumed that the diet has a great influence on the health of women and changes in body composition in postmenopausal women, it could be offset by an appropriate low diet in sugars, but does not prevent regular fat intake [23]. Also, the interest of this study is to see if the daily intake of two virgin oils widely used in Morocco-olive and argane oils, may have an influence on body composition in postmenopausal women.

This study showed that the population is predominantly recruited overweight even obese with a mean BMI of $28 \mathrm{~kg} / \mathrm{m}^{2}$ and an average body fat percentage of $40 \%$ of total body composition, with two methods: skinfolds and bioelectrical impedance analysis (BIA). Overall, these parameters are $40 \%$ higher than international standards [24]. In USA, the increase in FM in postmenopausal women, due to hormonal changes, can reach $26 \%$ of premenopausal FM $[24,25]$.

After stabilization, each woman has a specific physiology lipid status in relation to the quality of fat intake defined during this period. Therefore, the daily caloric intake remained constant and only the qualitative reports of saturated or unsaturated fatty acid were changed.

Through this study, the results showed that nutritional intervention based on argane oil or olive oil, has no significant effect on anthropometric profile of postmenopausal women, evaluated by measuring the weight, waist circumference and BMI. These results are consistent with the study conducted by Derouiche et al. [26], who reported that in adult men within a controlled environment, the daily consumption of argane oil has no effect on the anthropometric status $[26,27]$. Experiments in vivo on animal models showed that nutritional intervention based on dietary argane oil led to a significant decrease of body weight after six weeks, which was accompanied by reduction of blood lipoproteins, total cholesterol, low density lipoprotein (LDL)-cholesterol and triglycerides [28]. The beneficial effect of argane oil on human health was also reported by Ould-Mohamedou et al. [29], showing a great impact on lipid profile and LDL susceptibility to lipid peroxidation in both healthy subjects and dyslipidemic patients.

Regarding olive oil, large studies have been interested on the beneficial effect of olive oil consumption on human health. Even the impact of olive oil consumption has been largely studied, the effect on anthropometric parameters and body mass composition is still limited. Interestingly, a two months nutritional intervention on postmenopausal women showed that conjugated linoleic acids significantly reduced body weight and similar tendency in total and lower-body FM [30]. Experiments in animal models have shown that a controlled diet including olive oil with or without polyphenols causes no weight gain during the intervention period [31]. In addition, a similar study in a population of young women showed that after four weeks of nutritional intervention, a diet including olive oil shows no change in body weight in this population [32]. The beneficial impact of olive oil could be mainly due to the presence of oleuropein derivatives. Indeed, many studies strengthen the hypothesis that oleuropein derivatives play a major role in the health benefits of olive oil [33]. Oleuropein have several pharmacological properties, including anti-oxidant [33, 34] and anti-atherogenic [12]; and for these reasons, it is commercially available as a dietary supplement in the Mediterranean countries. In addition, it has been shown that oleuropein has cardio-protective effect against acute cardiovascular toxicity of adriamycin [35] and also an anti-ischemic 
and hypolipidemic effect [36].

Despite the relatively small numbers of women involved in this study and the relatively short duration of the intervention, the results clearly show that the caloric intake of argane and olive oils from the order of $207 \mathrm{kcal} / \mathrm{d}$ does not cause weight gain in postmenopausal women. However, it could not be assumed that the weight stagnation is not a consequence of energy expenditure. Unfortunately, the authors did not assess physical activity during the intervention, but they have emphatically recommended to all participant women to keep their lifestyles.

This regular and adequate fat intake is essential for proper functioning of the human body. It provides in part the energy for cellular metabolism, helps regulate body temperature as well as hormone synthesis, provides essential fatty acids and allows the absorption of micronutrients such as vitamins A, D, E and $\mathrm{K}$. To confirm the trend down that was recorded, probably a longer period of nutritional intervention is required.

\section{Conclusions}

In conclusion, both argane and olive oils show a positive impact on health, and the economic valuation of the argane and olive trees through its products is a way to restart sustainable integrated rural forestry. Indeed, previous research has shown that the argane tree is a future for certain arid areas. Thus, strengthening the scientific research is the key to success for any policy development and wealth creation and a key support to economic development.

The argane tree is a tree which risks disappearing, due to desertification and that goats eat young ones or people use it as firewood. Therefore, it becomes imperative to keep this universal heritage as sustainable resources. Showing the positive impact of the argane oil on human health adds more value to it and help to mobilize to safeguard this tree.

This paper shows that both argane and/or olive oils' regular diet, does not lead to weight gain, and postmenopausal women will benefit from their beneficial impact on health for a better quality of life and to overcome all menopause associated problems.

\section{References}

[1] Sowers, M., Zheng, H., Tomey, K., Karvonen-Gutierrez, C., Jannausch, M., Li, X., Yosef, M., and Symons, J. 2007. "Changes in Body Composition in Women over Six Years at Midlife: Ovarian and Chronological Aging." Journal of Clinical Endocrinology and Metabolism 92 (3): 895-901.

[2] Thurston, R. C., Sowers, M. F., Sternfeld, B., Gold, E. B., Bromberger, J., Chang, Y. F., Joffe, H., Crandall, C. J., Waetjen, L. E., and Matthews, K. A. 2009. "Gains in Body Fat and Vasomotor Symptom Reporting over the Menopausal Transition: The Study of Women's Health across the Nation." American Journal of Epidemiology 170 (6): 766-74.

[3] Heymsfield, S. B., Gallagher, C., Poehlman, E. T., Wolper, C., Nonas, K., Nelson, D., and Wang, Z. M. 1994. "Menopausal Changes in Body Composition and Energy Expenditure." Experimental Gerontology 29 (3-4): 377-89.

[4] Poehlman, E. T. 2002. "Menopause, Energy Expenditure and Body Composition." Acta Obstet. Gynecol. Scand. 81 (7): 603-11.

[5] Durnin, J. V. G. A., and Womersleya, J. 1974. "Body Fat Assessed from Total Body Density and Its Estimation from Skinfold Thickness: Measurements on 481 Men and Women Aged from 16 to 72 Years." British Journal of Nutrition 32: 77-97.

[6] Lichtenstein, A. H. 1997. "Trans Fatty Acids, Plasma Lipid Levels and Risk of Developing Cardiovascular Disease: A Statement for Healthcare Professionals from the American Heart Association." Circulation 95: 2588-90.

[7] Benatti, P., Peluso, G., Nicolai, R., and Calvani, M. 2004. "Polyunsaturated Fatty Acids: Biochemical, Nutritional and Epigenetic Properties." Journal of the American College of Nutrition 23 (4): 281-302.

[8] Hariri, N., Gougeon, R., and Thibault, L. 2010. "A Highly Saturated Fat-Rich Diet Is More Obesogenic than Diets with Lower Saturated Fat Content." Nutrition Research 30 (9): 632-43.

[9] Mascioli, E. A., McLennan, C. E., Schaefer, E. J., Lichtenstein, A. H., Høy, C. E., Christensen, M. S., and Bistrian, B. R. 1999. "Lipidemic Effects of an Interesterified Mixture of Butter, Medium-Chain Riacylglycerol and Safflower Oils.” Lipids 34 (9): 889-94.

[10] WHO. 2003. Diet, Nutrition and Prevention of Chronic 
Diseases. (in French)

[11] Visioli, F., Bellosta, S., and Galli, C. 1998. "Oleuropein, the Bitter Principles of Olives, Enhances Nitric Oxide Production by Mouse Macrophages." Life Sci. 62 (6): 541-6.

[12] Carluccio, M. A., Siculella, L., Ancora, M. A., Massaro, M., Scoditti, E., Storelli, C., Visioli, F., Distante, A., and De Caterina, R. 2003. "Olive Oil and Red Wine Antioxidant Polyphenols Inhibit Endothelial Activation: Antiatherogenic Properties of Mediterranean Diet Phytochemicals." Arterioscler. Thromb. Vasc. Biol. 23 (4): 622-9.

[13] Dubois, V., Breton, S., Linder, M., Fanni, J., and Parmentier, M. 2007. "Fatty Acid Profiles of 80 Vegetable Oils with Regards to Their Nutritional Potential.” Eur. J. Lipid Sci. Technol. 109 (7): 710-32.

[14] Hilali, M., Charrouf, Z., Soulhi, A. E. A., Hachimi, L., and Guillaume, D. 2005. "Influence of Origin and Extraction Method on Argan Oil Physico-Chemical Characteristics and Composition." J. Agric. Food Chem. 53 (6): 2081-7.

[15] Kazantzis, I., Nanos, G. D., and Stravoulakis, G. G. 2003. "Effect of Harvest Time and Storage Conditions on Almond Kernel Oil and Sugar Composition.” J. Sci. Food Agric. 83 (4): 354-9.

[16] Khallouki, F., Younos, C., Soulimani, R., Oster, T., Charrouf, Z., Spiegelhalder, B., Bartsch, H., and Owen, R. W. 2003. "Consumption of Argan Oil (Morocco) with Its Unique Profile of Fatty Acids, Tocopherols, Squalene, Sterols and Phenolic Compounds Should Confer Valuable Cancer Chemopreventive Effects." Eur. J. Cancer Prev. 12 (1): 67-75.

[17] Fellat-Zarrouk, K., Smoughen, S., and Maurin, R. 1987. "Study of the Pulp of the Fruit of the Argan Tree (Argania spinosa) in Morocco: Fat and Latex Material.". Actes Inst. Agron. Vét. 7: 17-22. (in French)

[18] El-Monfalouti, H., Charrouf, Z., El-Hamdouchi, A., Labraimi, H., Chafchaouni-Moussaoui, I., Kartah, B., El-Kari, K., Bensouda, Y., Derouich, A., Dodin, S., Denhez, C., Guillaume, D., and Agnaou, H. 2013. "Argan Oil and Postmenopausal Moroccan Women: Impact on the Vitamin E Profile." Natural Product Communications 8 (1): 55-7.

[19] Chapelot, D., Fumeron, F., and Fricker, J. 1998. "Dietary Fat, Energy Density and BMI: A Case of Missing Flower." Int. J. Obes. Relat. Metab. Disord. 22 (10): 1032-4.

[20] Dodin, S., Lemay, A., Jacques, H., Légaré, F., Forest, J. C., and Mâsse, B. 2005. "The Effects of Flaxseed Dietary Supplement on Lipid Profile, Bone Mineral Density and Symptoms in Menopausal Women: A Randomized, Double-Blind, Wheat Germ Placebo-Controlled Clinical
Trial.” J. Clin. Endocrino. Metab. 90 (3): 1390-7.

[21] Lohman, T. G., Roche, A. F., and Martorell, R. 1988. Anthropometric Standardization Reference Manual. Champaign, IL: Human Kinetics Press.

[22] Lohman, T. G., Roche, A. F., and Martorell, R. 1992. Anthropometric Standardization Reference Manual. Abridged Edition. Canada: Human Kinetics Publishers.

[23] Hare-Bruun, H., Flint, A., and Heitmann, B. L. 2006. "Glycemic Index and Glycemic Load in Relation to Changes in Body Weight, Body Fat Distribution and Body Composition in Adults Danes." American Journal of Clinical Nutrition 84 (4): 871-9.

[24] Lovejoy, J. C. 2009. "Weight Gain in Women at Midlife: The Influence of Menopause.” Obesity Management 5 (2): 52-6.

[25] Costa, P. R., Assis, A. M., Silva-Mda, C., Santana, M. L., Dias, J. C., Pinheiro, S. M., and Santos N. S. 2009. "Change in Anthropometric Parameters: The Impact of a Nutritional Intervention Program and Physical Exercise on Adult Women." Cad. Saude Publica. 25 (8): 1763-73. (in Portuguese)

[26] Derouiche, A., Cherki, M., Drissi, A., Bamou, Y., El-Messal, M., Idrissi-Oudghiri, A., Lecerf, J. M., and Adlouni, A. 2005. "Nutritional Intervention Study with Argan Oil in Man: Effects on Lipids and Apolipoproteins." Annals of Nutrition and Metabolism 49 (3): 196-201.

[27] Golay, A., and Bobbioni E. 1997. "The Role of Dietary Fat in Obesity." International Journal of Obesity and Related Metabolic Disorders 21 (3): S2-11.

[28] Berrougui, H., Ettaib, A., Herrera Gonzalez, M. D., Alvarez-Sotomayor, M., Bennani-Kabchi, N., and Hmamouchi, M. 2003. "Hypolipidemic and Hypocholesterolemic Effect of Argan Oil (Argania spinosa L.) in Meriones shawi Rats." Journal of Ethnopharmacology 89 (1): 15-8.

[29] Ould-Mohamedou, M. M., Zouirech, K., El-Messal, M., El-Kebbaj, M. S., Chraibi, A., and Adlouni, A. 2011. "Argan Oil Exerts an Antiatherogenic Effect by Improving Lipids and Susceptibility of LDL to Oxidation in Type 2 Diabetes Patients." Int. J. Endocrinol. 10: 747-835.

[30] Raff, M., Tholstrup, T., Toubro, S., Bruun, J. M., Lund, P., Straarup, E. M., Christensen, R., Sandberg, M. B., and Mandrup, S. 2009. "Conjugated Linoleic Acids Reduce Body Fat in Healthy Postmenopausal Women." J. Nutr. 139 (7): 1347-52.

[31] Benkhalti, F., Prost, J., Paz, E., Perez-Jimenez, F., El-Modafar, C., and El-Boustani, E. 2002. "Effects of Feeding Virgin Olive Oil or Their Polyphenols on Lipid of Rat Liver." Nutrition Research 22 (9): 1067-75.

[32] Ruiz-Gutierrez, V., Muriana, F. J. G., Guerrero, A., and 


\section{Postmenopausal Women in Morocco}

Villar, J. 1997. "Olive Oil and High-Oleic Sunflower Oil on Human Plasma and Erythrocyte Membrane Lipids." Nutrition Res. 17 (9): 1391-9.

[33] Omar, S. H. 2010. "Oleuropein in Olive and Its Pharmacological Effects.” Sci. Pharm. 78 (2): 133-54.

[34] Visioli, F., Poli, A., and Galli, C. 2002. "Antioxidant and Other Biological Activities of Phenols from Olives and Olive Oil." Med. Res. Rev. 22 (1): 65-75.

[35] Andreadou, I., Sigala, F., Iliodromitis, E. K., Papaefthimiou, M., Sigalas, C., Aligiannis, N., Savvari, P., Gorgoulis, V., Papalabros, E., and Kremastinos, D. T.
2007. "Acute Doxorubicin Cardiotoxicity Is Successfully Treated with the Phytochemical Oleuropein through Suppression of Oxidative and Nitrosative Stress." J. Mol. Cell Cardiol. 42 (3): 549-58.

[36] Andreadou, I., Iliodromitis, E. K., Mikros, E., Constantinou, M., Agalias, A., Magiatis, P., Skaltsounis, A. L., Kamber, E., Tsantili-Kakoulidou, A., and Kremastinos, D. T. 2006. "The Olive Constituent Oleuropein Exhibits Anti-ischemic, Antioxidative and Hypolipidemic Effects in Anesthetized Rabbits.” J. Nutr. 136 (8): 2213-9. 